\title{
BMJ Open Understanding clinician influences and patient perspectives on outpatient discharge decisions: a qualitative study
}

\author{
N A Harun, ${ }^{1}$ A Y Finlay, ${ }^{1}$ V Piguet, ${ }^{1}$ S Salek ${ }^{2}$
}

To cite: Harun NA, Finlay AY, Piguet $\mathrm{V}$, et al. Understanding clinician influences and patient perspectives on outpatient discharge decisions: a qualitative study. BMJ Open 2017;7:e010807. doi:10.1136/bmjopen-2015010807

- Prepublication history and additional material is available. To view please visit the journal (http://dx.doi.org/ 10.1136/bmjopen-2015010807).

Received 8 December 2015 Revised 2 December 2016 Accepted 17 January 2017

CrossMark

\begin{abstract}
${ }^{1}$ Division of Infection and Immunity, Department of Dermatology and Wound Healing, School of Medicine, Cardiff University, Cardiff, UK ${ }^{2}$ School of Life and Medical Sciences, University of Hertfordshire, Hatfield, UK
\end{abstract}

Correspondence to Dr N A Harun; ainitaharun@gmail.com

\section{ABSTRACT}

Objective: To observe the influences on clinicians when discharging patients, to explore patients' perspectives concerning their discharge or follow-up decision and to identify what patients think is important for clinicians to consider when taking a discharge decision.

Design: Qualitative study involving observations of consultations and semistructured interviews with outpatients.

Setting: National Health Service outpatient clinics at a university hospital secondary referral centre.

Participants: 64 consultations were observed followed by 56 interviews with patients aged over 18 years.

Main outcome measure: Analysis of patients' perspectives and expectations concerning whether or not they were discharged.

Results: 25 types of influences were observed to be influencing the discharge decision process. All 31 discharged patients appeared to accept the clinicians' decision; however, $10(22 \%)$ of those patients later expressed disappointment. Patients' discontent was due to perceived clinicians' uncertainty in diagnosis (patients mentioning=2), poor acceptance of the diagnosis (2), disease not 'cured' (4), differing perception on medical needs (2), lack of concern for job demands (1), felt uninvolved in the decisionmaking (4), feeling rushed (3), prolonged open appointment (2), pushed to seek private care due to healthcare budget constraints (2), language barrier (1) and not keen to continue follow-up with general practitioner (2). Patients were happy when there was certainty of the diagnosis (19), clear treatment plan (16), advised on treatment side effects (7), given a contact number if symptoms recurred (4), considering their travelling and job demands (3).

Conclusions: This study highlights the importance of accurately perceiving patients' perspectives in ensuring the appropriateness of outpatient discharge. There was a disparity between patients' and clinicians perception on what was an appropriate discharge. This included discrepancies concerning diagnostic certainties, private healthcare as an alternative, need for easy reaccess and choice of words surrounding discharge. Medical education should include handling these issues.

\section{Strengths and limitations of this study}

Data were derived from direct consultation observations by a single observer. The qualitative method used, interviewing patients immediately after discharge, encouraged patients' honesty about their experiences, when reassured that their comments would not affect further treatment.

- The usage of a topic guide during interviews focused patients specifically on the discharge decision process.

- The study was based on only one centre and may not be a true reflection of discharged patients in general.

- The findings may have been affected by the clinic organisation or local discharge policies where it is possible that clinicians in a less busy clinic with more auxiliary support may interact with patients differently.

- The finding of inappropriateness of discharge was a largely unexpected outcome of this study and the methodology of the study had not been planned to explore this. A further qualitative study needs to be carried out, focusing on interviewing only patients who were 'unhappy' or dissatisfied with their discharge, to explore this important issue further.

\section{INTRODUCTION}

Outpatient discharge decision-making occurs across the whole of medicine; it has a critical influence on service efficiency and patient satisfaction but very little is known about it. There are 82.1 million UK outpatient hospital visits annually. ${ }^{1}$ At every consultation, the clinician takes an implicit or explicit decision to discharge or see the patient again. Clinicians are under pressure to discharge patients to increase capacity. ${ }^{2}$ Although strategies ${ }^{3-5}$ have aimed at reducing secondary care demand, patients still prefer to see consultants rather than general practitioners (GPs). ${ }^{6}$ Clinicians balance their perception of patients' needs, ethical 
awareness and the intricate influences surrounding discharge in order to take appropriate decisions. ${ }^{7}$ Patients' attitudes towards their disease, wishes and their behaviour are also key considerations. ${ }^{8}{ }^{9}$ Clinicians therefore have to contend with complex influences, including a possibly inaccurate perception of patients' expectations, ${ }^{8-10}$ and the desire to discharge 'difficult' patients ${ }^{8} 10^{11}$ while continuing to review patients they know well. ${ }^{8} 9$ There is a real risk of biased clinician decision-taking. ${ }^{8} 12$

Few studies ${ }^{13-16}$ have examined what outpatients think about their discharge. Seeking to understand patients' views ${ }^{17-19}$ may improve patients' discharge experience. Considering patients' wishes over follow-up preference may minimise unneeded appointments. Improved communication $^{8} \quad 9 \quad 15 \quad 17-19$ and explanation of reasons behind discharge ${ }^{9}$ may alleviate distress. Lack of planning of care around discharge ${ }^{15}$ may result in an unhappy patient and family: incorporating patients' perspectives in the discharge process is critical. ${ }^{7} 815-19$

The main aim, that is the overall objective of this study, was to explore patient views about the outpatient discharge process, based on their recent experience. The research questions, that is, the current objectives that this study was designed to answer, were as follows: (1) to observe what influenced clinicians before discharging patients, (2) to explore patients' perspectives concerning their discharge or follow-up decision and (3) to identify what patients think is important for clinicians to consider when taking a discharge decision.

\section{METHODS}

\section{Participants}

The study took place in a general dermatology adult outpatients clinic at the University Hospital of Wales, Cardiff and consisted of observation of consultations immediately followed by general dermatology adult male and female patient interviews. NAH, first author and female researcher, conducted the interviews. She undertook this research as part of a wider $\mathrm{PhD}$ project and thereby was highly motivated to maximise information received from the participants. The assumptions were made that the interviewer biased will be minimised by one person carrying out the interviews. NAH is a clinician trained in internal medicine and dermatology. She received training in qualitative interview and transcription analysis, and conducted mock interviews before interviewing participants. A study protocol, patient information sheet and patient topic guide were emailed to all consultants in the department, seeking their permission to observe consultations and have their patients interviewed.

\section{Sampling}

The study participants were selected from a convenience population using purposive sampling methods. The convenience population was the population of general adult dermatology outpatients attending the outpatient clinics. 'Purposive' sampling is a type of non-probability sampling technique. Since this study was about understanding how adult dermatology outpatients were discharged from the clinic, the participants were selected, based on the judgement of the researcher $\mathrm{NAH}$, because they were dermatology patients attending outpatient clinics with the likelihood of being discharged. We considered the optimum sample size of interviewees, being informed by a previous study ${ }^{16}$ where saturation of information from interviewees was achieved at the 46th face-to-face interview and recruited an additional 15 patients to avoid bias and increase the robustness of the data.

\section{The recruitment process}

Recruitment strategy was to include a variety of patients of different gender, ages, job and education status and a variety of skin conditions, simple, complex, medical and surgical. The researcher selected clinic sessions which had both surgical and medical patient attendances. Recruitment was aimed at patients who were likely to be discharged. Before each clinic session, the consultant reviewed the patient appointment list and case notes and informed the researcher of patients who were 'potential' candidates for the study. The researcher would agree or disagree with the consultant's suggestion based on the demographic characteristics of patients whom she had interviewed earlier, in an attempt to recruit patients with a wide range of demographic characteristics and diseases. The cooperation of the consultant was critical because of his/her background knowledge of patients' problems, circumstances and disease severity.

When a patient was called in to the consultation room, the consultant sought verbal consent for the consultation to be observed. The researcher was then introduced to the patient and the patient's agreement reconfirmed. Following the consultation, the consultant would again check the patient's agreement and the researcher then interviewed the patient in a separate room. After each interview, the researcher would wait for the consultant to call her in for the next patient. It was difficult to keep a good balance of surgical and medical cases because most of the patients who refused to be interviewed were those with complex medical skin conditions. NAH did not know any of the participants before the study started. The participants only knew that $\mathrm{NAH}$ was a dermatology clinician who is currently a fulltime researcher.

\section{Data collection and analysis}

In the study, 64 consultations were observed and 56 patients were interviewed.

\section{Consultation observations}

The aim of the consultation observations was to observe what influenced clinicians before discharging patients. 
The observations of patients' discharge during the consultations with consultants were used to complement the subsequent patient interviews. The researcher's status as a non-participant observer was made clear to consultants and participants. Extracting what influences the consultants' discharge decision-taking process can be difficult because the observer can only make assumptions concerning these influences. In order to make note-taking of observations of consultations more structured, a 'Consultation Observation Checklist' was used (see online supplementary appendix 1) to record observations of how clinicians took discharge decisions. The checklist was developed based on discharge influences identified in the literature review and from previous clinicians' interviews. ${ }^{8-10}$ It was impossible to collect everything during the observation process; therefore, it was necessary to gain early insight into what interactions take place during the decision process. ${ }^{20}$ The question, "How was the consultant's demeanour?" within the 'Consultation Observation Checklist' was designed to address whether, and if so how, the intents and ethos described by the consultants were enacted in practice. For example, as some consultants in a previous study ${ }^{7}$ had stated that they displayed empathy when informing patients of their discharge, we used the observational approach to observe whether this was reflected in practice. The researcher observed the participants' speech, facial expressions and gestures used ${ }^{21}$ during their discussions with patients. The researcher also noted whether the consultants tried to make sure that patients understood their diagnosis and how to self-manage before discharging them. The observation method was used to understand consultant behaviour within a naturalistic context, complementing, verifying and validating data extracted from participant interviews. ${ }^{21}$

During the observation of consultations, the researcher NAH made multiple notes of any other aspects of the consultations that appeared to be of relevance, including recording the consultants' demeanour. In addition, the researcher observed the type of factors influencing the consultants' discharge decision-taking and recorded each influence using the 'Consultation Observation Checklist'.

The checklist data were analysed by counting the number of checklist influences recorded during each consultation and also by counting the number of consultations in which each influence occurred. These data were converted to percentages to make the comparison clearer. The checklist was piloted in eight consultation observations and altered based on that experience. New items not in the original 'Consultant Observation Checklist' were added, including 'Discharged due to a wrong referral'.

The structured recording of data assisted the subsequent manual analysis of how frequently these influences occurred with each consultant and in relation to the context of the decision being made. After each observation, the researcher looked through each influential factor and related it to the discharge or follow-up decision. The checklist helped us to identify patterns of what clinicians considered most before discharging patients and to understand how different patients were handled. For instance, observing the clinicians' demeanour made it possible to compare how clinicians reacted to different patients during the discharge decision-making process. The consultant's demeanour, as well as the patient's verbal and non-verbal responses such as facial expressions, was correlated with the list of influential factors. These observations were also interlinked with the clinic ambience and circumstances which occurred during the whole discharge decisionmaking process. For example, one consultant asked an elderly patient whether she could apply the cream at home and be discharged, but the patient insisted on a follow-up because of the lack of assistance since she was living on her own. Each consultation was analysed using this method. Outcomes which were similar were categorised under the same heading (influential factor). One of the limitations of this data analysis was that categorical data handling may result in a conceptual grid and there may be new categories or influences missed. However, this limitation was addressed by the pilot observation study.

\section{Patient interviews}

The aims of the patient interviews were to explore patients' perspectives concerning their discharge or follow-up decision and to identify what patients think is important for clinicians to consider when taking a discharge decision. Immediately after the consultation, patients were invited for an interview. After giving written consent, patients were interviewed face to face using a topic guide (see online supplementary appendix 2) and it was audio recorded. At the interview end, a question such as "is there anything more you would like to add?" was asked to encourage further patient ideas. We planned to interview at least 10 more patients after reaching saturation. No repeat interviews were carried out and the participants did not provide feedback on the findings. It would have been ideal for the researcher to interview each consultant immediately after the observation session to confirm whether each factor really had an influence on the discharge decisionmaking process. However, the prime focus of this study was to gain the patients' insights.

\section{Coding themes and subthemes of the data set}

Field notes were made during the interviews and reflective notes afterwards. Transcripts were not returned to participants for comment. Three of the authors were involved in the data coding (figure 1). Interviews were transcribed and manually analysed by coding data in the printed transcript margin.

In this study, a thematic analysis was conducted which involved searching repeated patterns (themes) across all data sets. A theme captures something significant or 


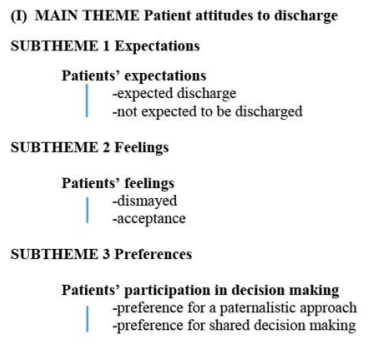

(II) MAIN THEME Key clinical considerations when taking discharge decisions

SUBTHEME 1 Diagnostic certainly, treatment plan and patient well informed

Well informed

-Clinician experience
-Clinician's expertis

-Clinician's expertise
-Confidence

Project confidence

Information

Certainty

-Diagnosis

-Investigation

Complete
Treatment

Good response

Coomplete
-Treatment plan

Clarity in treatment plan

-Cure

SUBTHEME 2 Patients' ability to cope and self-manage

Coping with the disease

| -Diagnosis

Acceptance of diagnosis

-Treatment
Understanding of medication

Able to self-manage
Presence of a carer

General practitioner

-Knowledgeable
-Type of practice

-Relationship with patient

SUBTHEME 3 Communicate with patient and address concerns

Effective communication

-Use of simple terms to convey informatio

nician's mannerisms
Show empathy

Show empathy
Project confidence

Unrushed and relaxed

Consider whether patient is happy to be discharge

-Explain reasons for discharge
-Perceive accurately patients' needs or wishes

-Reassurance.

Shared decision making

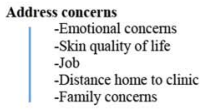

SUBTHEME 4 Efficient clinic organisation and clinical practice

Efficient clinic organisation

-Easy re-access to secondary care

-Shorter waiting list for specialist care

-Open appointment
-Support from clinical staff

Support from clinical s

Efricient clinical practic

Good Dermatologist-GP coordination and communication

-Notice of possible discharge

Able to see same clinician for appointments prior to discharge

(III) MAIN THEME Factors contributing to inappropriate discharge

SUBTHEME 1 Diagnosis related

Ciniclan's uncertainty of the diagnosis

Clinician's non-acceptance of final diagnosis

-Clinician's inappropriate discharge of patients with 'rare' diseases

SUBTHEME 2 Treatment related

the disense

-Differing perceptions between medical and cosmetic need

-lincomplete investigation

Poor monitoring

SUBTHEME 3 Patient disagreement with clinician's discharge practice

Climician's poor understanding and lack of concerm of patient's job deman

(n) patients' interests

Inappropriate referral to a private dermatologi
Eailure to provide open clinic appointment

SUBTHEME 4. Projection of a "rushed" demeanour

- Appear rushed

-Lack of consultation time

-Manner of speech

Figure 1 Details of the coding main themes and subthemes. $\mathrm{GP}$, general practitioner. meaningful about the data set in relation to the overall research question and is not necessarily dependent on how little or often such a theme appears throughout the data set. The researcher's judgement is critical to decide what a theme is. The researcher (NAH) transcribed the interviews and reviewed the data, as well as generated initial codes in a structured fashion and collated the codes into potential themes. These themes were then checked to confirm whether they related well to the coded extracts within the entire data set, and finally, each theme was clearly defined and named. ${ }^{22}$

Duplications were removed and similar categories grouped and reduced into broader subthemes. Research team members independently validated $10 \%$ of transcripts against recordings and resolved differences through discussion. Analysis focused on the patients' perception of discharge appropriateness, patients' discharge expectations and what they thought clinicians should consider before discharging them. Transcripts were further analysed using NVivo V.10, Qualitative Data Analysis Software to aid data organisation.

\section{Statistical analysis}

A 'descriptive statistical analysis' of the data is reported. This consists of reporting percentages of items observed.

\section{RESULTS}

\section{Consultation observations}

Participants (consultants)

Observations of 64 dermatology consultations took place in a dermatology outpatient clinic. Table 1 describes the characteristics of the dermatology consultants who took part. All but one consultant agreed to participate.

Table 1 Demographic characteristics of the consultant dermatologists $(\mathrm{N}=7)$

\begin{tabular}{lc}
\hline Consultant dermatologists & Number (N) \\
\hline Male & 5 \\
Female & 2 \\
Mean age (range) & 50.8 years (38-56) \\
Indigenous British & 4 \\
Ethnic minority & 3 \\
Type of NHS Contract & \\
Full time & 7 \\
$\quad$ Part time & 0 \\
Also working in private practice & 3 \\
Years of clinical experience in dermatology (years) \\
$30-40$ & 2 \\
$20-29$ & 3 \\
10-19 & 1 \\
$\quad<10$ & 1 \\
Main special interest in dermatology & \\
Medical & 4 \\
Surgical & 2 \\
Paediatric & 1 \\
NHS, National Health Service. &
\end{tabular}


Influences on discharge decisions

Table 2 describes the number of consultations, of the total 56, in which each 'Consultation Observation Checklist' influence was observed.

Twenty-five types of influences were observed to be influencing the discharge decision process. Table 3 presents the relationship of observed influential factors to the likelihood of discharge or follow-up, based on the 'Consultant Observation Checklist' and other recorded observations.

During the observation of consultations, the gender, ethnicity and years of experience of consultants were not perceived to relate to patients' satisfaction or dissatisfaction concerning the decision whether or not to discharge them. However, one patient with a different ethnic background to the consultant had difficulty understanding the disease management plan and the patient was not discharged. Consultants who worked in private practice appeared to be more confident in providing information to patients if the skin condition was not treatable under the National Health Service (NHS).

\section{Pattern of discharge of practice}

The pattern of discharge practice differed depending on various influences. Consultants had their own personal demeanour and unique method when handling

Table 2 Number of consultations in which each 'Consultation Observation Checklist' influence was observed (56 consultations observed)

\begin{tabular}{|c|c|c|}
\hline & $\begin{array}{l}\mathrm{N}=\text { Number of consultations in which } \\
\text { the influences were observed }\end{array}$ & Percentage (\%) \\
\hline \multicolumn{3}{|l|}{ Disease-based influence } \\
\hline Type of diagnosis & 56 & 100 \\
\hline Certainty of the diagnosis & 39 & 70 \\
\hline Disease progression & 26 & 46 \\
\hline Comorbidities & 15 & 27 \\
\hline Type of treatment & 41 & 73 \\
\hline Response of treatment & 38 & 68 \\
\hline Completion of treatment & 20 & 36 \\
\hline Treatment side effects & 12 & 21 \\
\hline Disease monitoring & 28 & 50 \\
\hline Usage of dermatology treatment guidelines & 5 & 9 \\
\hline \multicolumn{3}{|l|}{ Patient-based influence } \\
\hline Age & 3 & 5 \\
\hline Gender & 0 & 0 \\
\hline Culture & 0 & 0 \\
\hline Communication (language barrier) & 2 & 4 \\
\hline Mobility & 0 & 0 \\
\hline Distance & 5 & 9 \\
\hline Circumstances surrounding patient's life & 0 & 0 \\
\hline Carer or family member to assist at home & 19 & 34 \\
\hline Cognitive ability & 0 & 0 \\
\hline Learning difficulties & 0 & 0 \\
\hline Psychological concerns & 2 & 4 \\
\hline Patient's quality of life & 4 & 7 \\
\hline Understanding of the disease & 0 & 0 \\
\hline Patient's acceptance of disease & 28 & 50 \\
\hline Patient's ability to self-manage treatment & 36 & 64 \\
\hline Patient's compliance with medication & 0 & 0 \\
\hline Patients' initiative to engage with support groups & 0 & 0 \\
\hline Patient's concerns about job & 3 & 5 \\
\hline Patient's expresses wish to be discharged & 2 & 4 \\
\hline \multicolumn{3}{|l|}{ Practice-based influence } \\
\hline Academic interest & 5 & 9 \\
\hline Reassure patient easy reaccess to secondary care & 27 & 48 \\
\hline Joint colleague discussion & 7 & 13 \\
\hline Nurse assisted in explaining treatment & 3 & 5 \\
\hline Ascertain patient-GP relationship & 2 & 4 \\
\hline Ascertain GP's skills in handling dermatology cases & 2 & 4 \\
\hline Ascertain GP's willingness to share care & 0 & 0 \\
\hline Ascertain availability of treatment in secondary care & 16 & 29 \\
\hline Discharge due to wrong referral & 0 & 0 \\
\hline
\end{tabular}


Table 3 Relationship of observed influential factors to likelihood of discharge or follow-up)

\begin{tabular}{|c|c|c|}
\hline $\begin{array}{l}\text { Observed influential } \\
\text { factors }(\mathrm{N}=25)\end{array}$ & $\begin{array}{l}\text { Patient is likely* to be discharged if the } \\
\text { influence aspect (column 1) is as follows: }\end{array}$ & $\begin{array}{l}\text { Patient is likely* to be followed up if the } \\
\text { influence aspect (column 1) is as follows: }\end{array}$ \\
\hline Type of diagnosis & Disease is self-limiting or simple & Disease is severe or complex \\
\hline Certainty of the diagnosis & Diagnosis is confirmed & Biopsy is needed to confirm diagnosis \\
\hline $\begin{array}{l}\text { Patient's acceptance of } \\
\text { the diagnosis }\end{array}$ & Understands and able to accept diagnosis & Doubtful about diagnosis accuracy \\
\hline Type of referral & Wrong referral & Appropriate referral \\
\hline $\begin{array}{l}\text { Joint colleague discussion } \\
\text { to confirm diagnosis }\end{array}$ & Clinician is confident of diagnosis & $\begin{array}{l}\text { Clinician is unsure of diagnosis, needing joint } \\
\text { colleague discussion to confirm diagnosis }\end{array}$ \\
\hline Comorbidities & Patient with no other problems & Patient with multiple diagnoses \\
\hline Guidelines & Treatment which does not involve guidelines & $\begin{array}{l}\text { Treatment which involves guidelines (such as } \\
\text { for melanoma) }\end{array}$ \\
\hline Disease progression & Stable or asymptomatic & Recurrent \\
\hline Disease monitoring & $\begin{array}{l}\text { Treatment plan which can be monitored by } \\
\text { GP }\end{array}$ & $\begin{array}{l}\text { Treatment plan which needs hospital } \\
\text { monitoring }\end{array}$ \\
\hline Type of treatment & Topical treatment with minimal side effects & Ongoing systemic medication or biologics \\
\hline $\begin{array}{l}\text { Completion of treatment or } \\
\text { 'cured' }\end{array}$ & Tumour fully resected & Multiple tumours and recurrent tumours \\
\hline Treatment response & Good treatment response & Poor treatment response \\
\hline Treatment availability & $\begin{array}{l}\text { Not available or treatment not possible in the } \\
\text { NHS }\end{array}$ & Many treatment options available in the NHS \\
\hline Patient age & Younger patients & Older and frail patients \\
\hline Patient attitude & Patients who appear confident & $\begin{array}{l}\text { Patients who have a long-term relationship } \\
\text { with consultant }\end{array}$ \\
\hline Carer & Presence of carer or family & Living alone \\
\hline Communication & Ability to communicate well & Language barrier \\
\hline Job & Busy & Retired \\
\hline Distance & Lives away and travelling difficulties & Easily mobile, independent \\
\hline Psychosocial concerns & None & $\begin{array}{l}\text { Present and lack of resources to handle } \\
\text { concerns }\end{array}$ \\
\hline Skin disease burden & Coping well & Not coping well. \\
\hline Self-manage & $\begin{array}{l}\text { Understood well and agreed to self-monitor } \\
\text { disease }\end{array}$ & $\begin{array}{l}\text { Difficulties in coping or lack of support to } \\
\text { monitor disease }\end{array}$ \\
\hline GP relationship & Good relationship with GP & Doubtful of GP's expertise \\
\hline GP's skills & $\begin{array}{l}\text { Skilful GP or GP with dermatosurgical } \\
\text { facilities }\end{array}$ & Perceived inadequate GP dermatology skills \\
\hline Wishes or concerns & $\begin{array}{l}\text { Patient accepts advice after addressing } \\
\text { wishes or concern }\end{array}$ & $\begin{array}{l}\text { Unrealistic expectations or too many concerns } \\
\text { making it impossible to handle in one clinic } \\
\text { setting }\end{array}$ \\
\hline
\end{tabular}

*“...is likely" refers to the opinion of the researcher NAH, based on witnessing and recording the 64 consultations. NAH was also informed by interviewing 56 patients, spending over 100 hours transcribing and reflecting on the interviews' content and by detailed discussions with the research team.

GP, general practitioner; NHS, National Health Service.

discharge: all maintained good eye contact and expressed concern. Twenty-six $(46 \%)$ consultations were interrupted by colleagues or by phone calls. Consultants kept within the standard consultation time when the problem was simple. However, six consultants spent longer with patients who had special concerns about their skin. Before discharging a patient referred for a diagnosis (after many years of uncertainty), the consultant took time to explain the diagnosis, treatment possibilities and that cure was unlikely. When interviewed, the patient said she was less anxious, relieved to have a confirmed diagnosis and was happy to be discharged (Quotation 1). The possible implications to this finding require further thought and development of strategies to improve clinic discharge management by reducing disruption of clinic consultations. As part of a wider study, ${ }^{8} 40$ consultants were asked about the strategies that could be used to improve discharge decision-taking: one of these was to train juniors in effective time management. All consultants clearly explained the diagnosis to patients: in two instances, the diagnosis was ambiguous but the patient was discharged after reassurance. Patients accepted their discharge readily after a good surgical outcome. An elderly patient appeared relieved when not discharged: she stated that despite normal clinical findings, she was followed up because the consultant had cared for her for years and understood her well. If treatment was complex and needed primary care blood monitoring, consultants tended to check on the patient's motivation to self-monitor. When discharging, 
one consultant always concluded by asking "Is there anything else I can help you with right now?”

\section{Patient interviews}

Participants (patients)

Fifty-six patients with medical, surgical, subacute and chronic skin conditions were interviewed immediately after their consultation had been observed (26 (46\%) male, mean age 54 years, range $18-80$ ). Table 4 presents the demographic characteristics of the patients. Sixty-four patients (excluding the pilot study) initially agreed to be observed and interviewed. However, eight patients later changed their minds because four were in a hurry, three had other commitments and one because of poor English resulting in poor communication.

Table 4 Demographic characteristics of the patients who were interviewed and whether they were discharged or not

\begin{tabular}{|c|c|c|c|c|}
\hline Study participants & Number & $\begin{array}{l}\text { Percentage } \\
(\%)\end{array}$ & Discharged & $\begin{array}{l}\text { Not } \\
\text { discharged }\end{array}$ \\
\hline Male & 26 & 46 & & \\
\hline Female & 30 & 54 & & \\
\hline Mean age (range) & 53.9 years $(18-80)$ & & & \\
\hline Indigenous British & 50 & 89 & & \\
\hline Ethnic minority & 6 & 11 & & \\
\hline \multicolumn{5}{|l|}{ Education level } \\
\hline Primary & 1 & 2 & & \\
\hline Secondary & 31 & 55 & & \\
\hline Tertiary & 24 & 43 & & \\
\hline \multicolumn{5}{|l|}{ Type of skin disease } \\
\hline Medical & 29 & 52 & & \\
\hline Surgical & 24 & 43 & & \\
\hline Unconfirmed diagnosis & 3 & 5 & & \\
\hline \multicolumn{5}{|l|}{ Type of job } \\
\hline Employed & 19 & 34 & & \\
\hline Self-employed & 4 & 7 & & \\
\hline Retired & 28 & 50 & & \\
\hline University student & 3 & 5 & & \\
\hline Unemployed on benefits & 2 & 4 & & \\
\hline \multicolumn{5}{|l|}{ Diagnosis } \\
\hline Non-melanoma skin cancer & 7 & $13 \%$ & 3 & 4 \\
\hline Melanoma & 1 & $2 \%$ & & 1 \\
\hline Eczema & 5 & $9 \%$ & 1 & 4 \\
\hline Psoriasis & 3 & $5 \%$ & & 3 \\
\hline Itchy rash & 1 & $2 \%$ & 1 & \\
\hline Acne vulgaris & 3 & $5 \%$ & 2 & 1 \\
\hline Postinflammatory hyperpigmentation & 2 & $4 \%$ & 1 & 1 \\
\hline Actinic keratosis & 4 & $7 \%$ & 3 & 1 \\
\hline Allergic contact dermatitis to latex & 1 & $2 \%$ & 1 & \\
\hline Benign mole & 2 & $4 \%$ & 2 & \\
\hline Ingrown hair & 1 & $2 \%$ & 1 & \\
\hline Melasma & 2 & $4 \%$ & 1 & 1 \\
\hline Skin cancer and renal transplant & 1 & $2 \%$ & & 1 \\
\hline Urticaria & 2 & $4 \%$ & 2 & \\
\hline Dermatofibroma & 2 & $4 \%$ & 1 & 1 \\
\hline Leg ulcer & 1 & $2 \%$ & & 1 \\
\hline Onychomycosis & 1 & $2 \%$ & 1 & \\
\hline Nodular prurigo & 1 & $2 \%$ & & 1 \\
\hline Lichen planus & 1 & $2 \%$ & 1 & \\
\hline Seborrhoeic dermatitis & 1 & $2 \%$ & 1 & \\
\hline Polymorphic light eruption & 4 & $7 \%$ & 3 & 1 \\
\hline $\begin{array}{l}\text { Photosensitive dermatitis, photoaggravated rosacea } \\
\text { and UVA sensitivity }\end{array}$ & 3 & $5 \%$ & 1 & 2 \\
\hline Insect bites & 2 & $4 \%$ & 1 & 1 \\
\hline Rosacea & 2 & $4 \%$ & 2 & \\
\hline Uncertain diagnosis & 3 & $5 \%$ & 2 & 1 \\
\hline Total & 56 & $100 \%$ & 31 & 25 \\
\hline
\end{tabular}




\section{Details of patient interviews}

Data saturation was achieved after 41 interviews: 15 more confirmed saturation. The mean interview time was $20 \mathrm{~min}$ (range 5-40 min). NAH undertook all observations and interviews. Patient quotations are given in online supplementary appendix 3 . In 17 interviews, a family member of the patient was present. All 31 discharged patients appeared to agree with the clinician's decision to discharge them. However, when interviewed, 12 had not expected discharge. Two of these were happy: one was given the reassurance of easy clinic reaccess and the other was relieved that the treatment had finished (Quotation 2). The other 10 patients were unhappy, critical of the clinicians' attitude and incorrect perception of their needs. Eight had chronic disorders and had been followed up over the long-term. Only two were at their first appointment. Three patients who had expected to be discharged were given a follow-up: one felt that there were limitations to the consultant's expertise, one perceived that no lesions were recurring and one felt that nothing more could be done.

Eleven subthemes were identified, classified under three main themes: (I) Patients' attitudes to discharge: (1) patients' expectations, (2) patients' feelings and (3) patients' participation in decision-making; (II) Key clinical considerations when taking discharge decisions: (1) diagnostic certainty, treatment plan and patient well informed, (2) patients' ability to cope and self-manage, (3) communicate with patients and address concerns and (4) efficient clinic organisation and clinical practice; (III) Factors contributing to inappropriate discharge: (1) diagnosis related, (2) treatment related, (3) patient disagreement with clinician's discharge practice and (4) projection of a 'rushed' demeanour.

\section{Coding themes and subthemes of the data set}

Details of the coding themes and subthemes are presented in figure 1.

\section{Patients' attitudes to discharge}

Patients' expectations

One patient with acne had not expected discharge despite significant improvement. He assumed he would not be discharged until completion of treatment. However, another similar patient was relieved to be discharged, inferring that his disease was controlled.

\section{Patients' feelings}

An elderly patient, who experienced slight nerve damage secondary to excision of a skin cancer, agreed to discharge without any concern. However, a university student was dismayed by the decision to discharge, although his facial seborrhoeic dermatitis was clearly improving with medication.

\section{Patients' participation in decision-making}

Retired patients were less likely to engage in the discharge discussion. They accepted a more paternalistic approach and were less likely to negotiate follow-up (Quotation 3). When interviewed, only two of the retired patients $(7 \%)$ preferred to have a discussion over whether or not to be discharged. Patients in employment and young adults apparently felt strongly that they should be involved in the discharge decision and two stated that they would inform their consultant if they did not agree with the decision (Quotation 4). Patients who had chronic or complex problems were keen to be involved in the decision-making and preferred to be notified in advance about the possibility of discharge. Patients with surgical disorders were less demanding, saying they were impressed with the department's services. However, two patients stressed that they should not have been discharged without the dermatology surgeon (preferably) inspecting the surgical wound.

\section{Key clinical considerations when taking discharge decisions \\ Diagnostic certainty, treatment plan and patient well informed}

Patients expected clinicians to be certain of their diagnosis $(n=39)$ and provide a clear treatment plan $(n=38)$. All stressed that providing clear information about their disease, patient information leaflets and website addresses is essential before discharge, empowering selfmanagement and enhancing their confidence. Most patients with chronic diseases felt 'safer' to be followed up, in case treatment needed changing. Fifty-one patients expected their management to be complete before discharge, including full investigation, exploring treatments and their responses and a final thorough examination (Quotation 5).

\section{Patients' ability to cope and self-manage}

Patients are reluctant to be discharged if they feel unable to detect subtle changes heralding worsening (Quotation 6). Three patients with psoriasis insisted that their disease chronicity meant they should never be discharged, even if well controlled, for fear of coping by themselves or missing new treatments. They felt more reassured being followed up by a dermatologist, even annually, than by their GP (Quotation 7): GPs need to have appropriate knowledge and to know when to re-refer.

\section{Communicate with patients and address concerns}

Patients preferred phrases such as: "I don't need to see you again" or "You can now be taken care of by your GP" to the blunter "You are discharged". Fifteen patients said that clinicians should use simple terms when providing information. However, during the observations, no clinicians used medical jargon. One (doctor) patient highlighted that clinicians should be reminded not to use medical jargon with a patient, to prevent them being confused (Quotation 8). Eight patients said that, when discharging, it is important that the physician has a confident demeanour to reassure the patient. Three 
patients mentioned that if a patient does not speak English, an interpreter must be used. During observations, in addition to the checklist items recorded (table 2), the researcher NAH noted that two discharged patients apparently did not understand the diagnosis. One patient noticed that the clinician was unimpressed by his spots until told they were itchy, illustrating the patients' sensitivity to doctors' mannerisms and body language (Quotation 9). Two patients felt it was important that clinicians ask whether patients are happy to be discharged (Quotation 10). However, one patient thought this was a redundant question because he did not think anything would have been done if he had replied that he was unhappy (Quotation 11).

\section{Efficient clinic organisation and clinical practice}

Seven patients were more likely to accept discharge if assured of quick reaccess to specialist care if necessary. Twenty patients felt that the long waiting time for first appointments or re-referrals was daunting. One patient with severe chronic urticaria said that he almost committed suicide because of intolerable pain and itch and the long delays in dermatology referral (Quotation 12). Patients were happy if they perceived good communication existed between dermatologists and GPs or other specialty consultants involved in their care. Those with comorbidities were most appreciative of the reassurance that after discharge they would still be in good hands. Five patients mentioned the importance of coordination between the GP and the specialist. Two patients stated that discharge was more acceptable when notice of possible discharge is given during a previous consultation or when, after biopsy, the consultant wrote to the GP confirming a benign diagnosis. However, a (nurse) patient thought otherwise (Quotation 13). Patients with chronic conditions felt that warning of discharge would allow their mental preparation. Two surgical patients were keen to see the clinician who operated on them before discharge, to give them reassurance of the surgery's success and a sense of completeness.

\section{Factors contributing to inappropriate discharge}

The following results are based on information from all patients who were interviewed, and were not restricted to the 10 'unhappy' patients.

\section{Diagnosis related}

Patients insisted that clinicians should confirm their diagnosis before discharge. One patient was unhappy because she felt that the clinician was uncertain of the diagnosis. She was asymptomatic because the lesions had resolved while waiting for her appointment. She mentioned at the interview that she would have preferred an open appointment for easy access should the symptoms recur rather than a fixed follow-up. However, she did not say this to the clinician. Two patients stressed that the patients' acceptance of their diagnosis is important before discharge. One patient was unhappy because he did not agree with the clinician's diagnosis and expected further investigations and monitoring. He was discharged because the clinician was confident of the diagnosis and explained that there was no other treatment. The patient felt that the clinician was only interested in his perception of the diagnosis and was unwilling to probe further (Quotation 14). Another patient referred for diagnosis was appropriately given a follow-up. She felt that patients with rare diseases should never be discharged before making a definite diagnosis (Quotation 15).

\section{Treatment related}

One patient felt that patients with conditions with no cure should never be discharged, because of possible future advances. One student with seborrhoeic dermatitis insisted that his problem must be 'cured' despite knowing that this condition may recur. A patient with melasma was upset because he thought that the clinician perceived his problem as purely cosmetic. A young woman with acne highlighted that clinicians should provide further suggestions for dealing with disease or treatment complications, such as scarring.

\section{Patient disagreement with clinician's discharge practice}

One patient stated that it was a hassle for her to be discharged and re-referred for surgical intervention if she later wanted this. She expected the clinician to understand her job demands and felt she should have been given more time to make a decision during the consultation. She said she was unable to express her disagreement due to her poor English and had felt uninvolved in the decision-making. Five patients were unhappy that their clinicians suggested they seek referral to a private dermatologist: actually, the clinicians were informing patients about treatment only available in the private sector. Two patients did not understand NHS service limitations and felt that the doctor was 'following the rules' rather than prioritising the patient's best interests (Quotation 16).

\section{Projection of a 'rushed' demeanour}

Three patients felt upset because their clinicians appeared rushed. The patients perceived that the clinician wanted to 'wrap up' the consultation and discharge them to save time. These patients were still uncertain of their diagnosis or had psychological problems. One patient said he did not express dissatisfaction because of how the clinician spoke (Quotation 17).

\section{DISCUSSION}

In this study, the mean age of patients was 54 years. Fifty-five per cent of dermatology outpatients range from age $45-100$ years. ${ }^{20}$ Forty-three per cent of the patients interviewed reported having had tertiary education. This is a higher level than that in the general population. This may be partially explained by the recruitment 
hospital being based in a large city centre where residents are generally well educated.

\section{Accurate perception and certainty of information}

The researcher observed that in all consultations in which the decision was taken to discharge the patient, all patients and dermatologists gave the impression of agreeing with and of being content with the decision to discharge. However, this study has revealed that there may be a major discordance between patients' demeanour and apparent acceptance of discharge decisions, giving the impression that they were content with the decision and patients' actual views. ${ }^{23}$ Although clinicians endeavoured to address patients' needs, expressed concern and confidently arranged discharge, they mainly focused on medical issues ${ }^{24}$ and were unaware of some patients' discontent over the discharge itself. Moreover, no patients objected to their discharge.

Clinicians may be unwittingly biased because of overconfidence, ${ }^{8}{ }^{25}$ or previous individual experiences. ${ }^{26}$ Skilled expertise ${ }^{27}$ is central to accurate clinical judgement; however, a standardised tooll $^{28}{ }^{29}$ might in some instances be helpful to prevent bias. ${ }^{8}$

Inpatients are sensitive to subtle nuances of clinicians appearing courteous but not truly curious about patients' expectations and needs. ${ }^{24}$ This study identified that outpatients also perceive these nuances, despite short consultations. Clinicians often focus on the basics of clinical medicine, such as diagnosing and monitoring treatment response. Just as inpatient discharge is problematic, ${ }^{15}$ outpatient clinics are usually very busy and clinicians have little time to make discharge decisions. If more time could be allocated to final visit consultations, this would allow more a detailed addressing of patients' concerns and possibly reduce some of the bias inherent when judgements are made.

Patients expect continuity of outpatient care until the diagnosis is certain, but this may not always be possible. If clinicians were able to provide relevant information ${ }^{8} 9$ to support understanding and self-care, this might increase patients' confidence in the discharge process. Jointly discussing a patient's treatment plan and encouraging further questions, ${ }^{30}$ even if a patient seems to accept discharge, could uncover unmet needs.

\section{Effective communication and patient engagement}

Effective clinician-patient communication is a core attribute of high quality discharge-making. ${ }^{9}{ }^{15}$ For example, the avoidance of use of medical jargon may contribute to an atmosphere in which patients feel encouraged to ask questions. ${ }^{13}$ If healthcare professionals, as part of the healthcare team, engage closely with patients with chronic conditions, the discharge decision process could be tailored to individual patient needs. The demeanour of clinicians has considerable unspoken influence on the consultation. Patients emphasised the importance of clinicians projecting confidence, respecting patients' views, using 'kinder' words at discharge and displaying empathy. Most dermatology patients left the discharge decision entirely to clinicians. If patients are involved in the treatment decision, ${ }^{31}$ even if disagreeing with the final decision, this may allow clinicians to gauge what matters most to a patient ${ }^{32}$ before the decision is made. Clinicians may miss subtle hints of patients' needs if they discount patients' personal accounts, ${ }^{25}$ dominate a subservient patient or ignore patient involvement in the decision process. ${ }^{15} 33$ If there are conflicting views on the final decision, this may encourage clinicians to try to understand the reasons for disagreement and thereby better inform their clinical judgement.

\section{Addressing concerns and patient reassurance}

Fully addressing all concerns of patients before discharge may in reality be impossible. Some patients felt 'short-changed' at not receiving the 'best' treatment for conditions with a strong cosmetic element. Aggressive discharge policies or tumour management guidelines may be challenged if patients express uneasiness at not being given a follow-up after surgery. Patient dissatisfaction might be reduced if clinicians ensured that patients understood the reasons behind hospital policies. Easy access to policy documents might enable this, if written in simple language. Dermatology patients are especially vulnerable to public comments of their appearance, because skin is integral to body image and self-respect. Although treatment was often not ideal, many patients interviewed preferred to be indefinitely under dermatology care. Difficulties arise because of a mismatch between clinicians thinking they have 'reassured' a patient and the patient's actual perception. ${ }^{34}$

Long re-referral waiting times add worry to patients already having difficulty coping. This concern may be addressed by making provision for open return appointments or direct access if needed. If patients are discharged with severe or chronic inflammatory skin disease that needs continued monitoring, a wellcoordinated management plan between the specialist and the $\mathrm{GP}^{9}{ }^{15}$ clearly explained to the patient, will enhance the quality of care. Prior notification of discharge may help alleviate anxiety. Patients need reassurance that they will receive quality care after discharge from outpatients. ${ }^{34}$ It may be helpful, especially for those patients who favour indefinite secondary care, to inform them of the framework of care provided by their $\mathrm{GPs}^{9}$ and of their suitability for follow-up in primary care. Identification of patients who need extra primary care input or emotional support after discharge may also result in the pre-empting of potential problems.

This study has some limitations. For example, it is possible that some of the personal characteristics of the consultants, such as age, gender or ethnicity, may have been relevant to the patients' perceptions or acceptance of the discharge decisions. Our study was not designed to address this question, but no patients commented on these personal characteristics of the consultants. 


\section{IMPLICATIONS AND FUTURE RESEARCH}

The degree to which patients accept discharge varies widely: each patient's level of concern arises from their individual belief system or expectations. Patient engagement in the discharge process could contribute to the appropriateness of discharge decisions. Up to now, the patients' voice in the discharge decision has largely been ignored. However, there is increasing motivation to ensure that clinical decisions are efficient and appropriate, to enhance care and for reporting performance. When taking the decision to discharge, clinicians using empathetic body language may help alleviate patients' anxiety. The clinical challenges require an appropriate mixture of coaxing and empathy along with the assessment of treatment response and consideration of the diagnosis. It would be appropriate to train clinicians to think and decide about discharge systematically: this would encourage clinicians to consider the patient's overall health, the clarity of the treatment plan, the patient's ability to apply treatment and to cope with treatment side effects. The wide range of issues identified by patients as important provides evidence to support targeted clinical training.

This study identifies for the first time that many patients on being discharged from outpatients may agree with the clinician to being discharged, apparently willingly, but in reality are unhappy with the decision or the way it was managed. It is important that clinicians should be aware of this possibility and seek to modify the way that they take discharge decisions to ensure that the patient's true feelings are taken into account. This flags up the need for clinicians to involve patients in discharge decision-making in a structured systematic manner.

\section{CONCLUSION}

This study highlights the importance of accurately perceiving patients' perspectives in ensuring the appropriateness of outpatient discharge. This study provides a warning to clinicians that discharging a patient is even more complicated than it seems, and has opened a Pandora's Box of patients' attitudes surrounding discharge decisions. It highlights the importance of considering patients' perspectives in ensuring the appropriateness of outpatient discharge. This may be addressed by clinicians trying to include patients in discharge decisions and by understanding and addressing their wishes, especially with dermatology patients whose confidence relates to their body image. There is a need for a systematic approach to develop a science of discharge. We need to ascertain which information is critical to consider prior to discharge ${ }^{35}$ and to understand how clinicians can gain an accurate perception of patients' expectations and avoid bias. Conflicting views relating to discharge will continue between some clinicians and patients unless clinicians more fully understand patients' expectations and are able to handle their concerns. Perhaps after beginning to hear the patient's voice surrounding discharge, clinicians should be encouraged to develop the skills needed to take consistently high quality and appropriate discharge decisions.

Acknowledgements The authors thank the patients and consultants in Cardiff who contributed to this study for their invaluable contribution.

Contributors NAH carried out literature search, study design, data collection, data analysis, data interpretation and wrote the first draft of the manuscript. She was instrumental in getting ethical and R\&D approval for the study. VP contributed to the study design, supervision of the project and writing of the manuscript. AYF and SS contributed to the study design, supervision of data collection, analysis of data and writing of the manuscript.

Funding NAH is funded by the University Malaya Medical Centre and The Council for Indigenous People of Malaysia (MARA). The funders had no role in the gathering or analysis of the data and no role in the writing of the manuscript or the decision to submit for publication.

Competing interests None declared.

Ethics approval South East Wales RECs Committee gave ethical approval. REC: 11/WSE03/4 Date approved: 24 February 2011. The participants gave informed consent before taking part in the study.

Provenance and peer review Not commissioned; externally peer reviewed.

Data sharing statement No additional data are available.

Open Access This is an Open Access article distributed in accordance with the Creative Commons Attribution Non Commercial (CC BY-NC 4.0) license, which permits others to distribute, remix, adapt, build upon this work noncommercially, and license their derivative works on different terms, provided the original work is properly cited and the use is non-commercial. See: http:// creativecommons.org/licenses/by-nc/4.0/

\section{REFERENCES}

1. Health \& Social Care Information Centre (2013-2014). Hospital outpatient activity. Available from: http://www.hscic.gov.uk/catalogue/ PUB16722 (accessed 25 Sep 2015).

2. Bamji A. Outpatient follow-up ratio targets make no sense. BMJ 2011;342:c7373.

3. Roman M, Jacob SE. Teledermatology: virtual access to quality dermatology care and beyond. J Dermatol Nurses Assoc 2014;6:285-7

4. Donnellan F, Hussain T, Aftab A, et al. Reducing unnecessary outpatient attendances. Int J Healthcare Qual Assur 2010;23:527-31.

5. Roland M, McDonald R, Sibbald B, et al. Outpatient services and primary care: a scoping review of research into strategies for improving outpatient effectiveness and efficiency. Manchester: National Primary Care Research and Development Centre, 2006.

6. Coast J, Salisbury C, De Berker D, et al. Preferences for aspects of a dermatology consultation. Br J Dermatol 2006;155:387-92.

7. Harun NA, Salek S, Piguet V, et al. The dermatology outpatient discharge decision: understanding a critical but neglected process. Br J Dermatol 2014;170:1029-38.

8. Harun NA, Finlay AY, Salek MS, et al. Appropriate and inappropriate influences on outpatient discharge decision-making in dermatology: a prospective qualitative study. Br J Dermatol 2015;173:720-30.

9. Burkey $\mathrm{Y}$, Black $\mathrm{M}$, Reeve $\mathrm{H}$, et al. Long-term follow-up in outpatient clinics. 2: the view from the specialist clinic. Fam Pract 1997;14:29-33.

10. Hajjaj FM, Salek MS, Basra MKA, et al. Nonclinical influences, beyond diagnosis and severity, on clinical decision-making in dermatology: understanding the gap between guidelines and practice. Br J Dermatol 2010;163:789-99.

11. Sampson F, Munro J, Pickin M, et al. Why are patients removed from their doctors' lists? A comparison of patients' and doctors' accounts of removal. Fam Pract 2004;21:515-18.

12. Bornstein BH, Emler AC. Rationality in medical decision-making: a review of the literature on doctors' decision-making biases. J Eval Clin Pract 2008;7:97-107.

13. Burkey $Y$, Black $M$, Reeve $H$. Patients' views on their discharge from follow-up in outpatient clinics: qualitative study. BMJ 1997;315:1138-41. 
14. Stokes T, Dixon-Woods M, Windridge KC, et al. Patients' accounts of being removed from their general practitioner's list: qualitative study. BMJ 2003;326:1316.

15. Hesselink $\mathrm{G}$, Flink $\mathrm{M}$, Olsson $\mathrm{M}$, et al. Are patients discharged with care? A qualitative study of perceptions and experiences of patients, family members and care providers. BMJ Qual Saf 2012;21(Suppl 1):i39-49.

16. Hajjaj FM, Salek MS, Basra MK, et al. Clinical decision-making in dermatology: observation of consultations and the patients perspectives. Dermatol 2010;221:331-41.

17. Snow R. Do you know what your patient is thinking? BMJ 2015;350: h375.

18. Ouyang $\mathrm{H}$. Art of discharge. JAMA 2015;313:2027-8

19. BMA Patient Liaison Group. Hospital discharge: the patient, carer and doctor perspective. http://bma.org.uk/news-views-analysis/news/ 2014/february/patient-and-doctor-partnership-comes-of-age (accessed 28 Nov 2014).

20. Silverman D. Interpreting qualitative data. 4th edn. London: Sage, 2011.

21. Ritchie J, Lewis J, Nicholls CM, et al. Qualitative research practice: a guide for social science students and researchers. Sage, 2013

22. Braun V, Clarke V. Using thematic analysis in psychology. Qual Res Psychol 2006;3:77-101.

23. Mühlbacher AC, Juhnke C. Patient preferences versus physicians' judgement: does it make a difference in healthcare decision-making? Appl Health Econ Health Policy 2013;11:163-80.

24. Agledahl KM, Gulbrandsen P, Førde R, et al. Courteous but not curious: how doctors' politeness masks their existential neglect. A qualitative study of video-recorded patient consultations. J Med Ethics 2011:37:650-4.
25. Croskerry $P$, Norman $G$. Overconfidence in clinical decision-making. Am J Med 2008;121:S24-S9.

26. Kahneman D. Thinking fast and slow.UK: Penguin Group, 2011:381-4.

27. Kahneman D, Klein G. Conditions for intuitive expertise: a failure to disagree. Am Psychol 2009;64:515-26.

28. Kini SP, DeLong LK, Veledar E, et al. The impact of pruritus on quality of life: the skin equivalent of pain. Arch Dermatol 2011;147:1153-6.

29. Finlay AY. Dermatologists should better integrate quality-of-life measures to inform and improve clinical decision-making: comment on "The Impact of Pruritus on Quality of Life". Arch Dermatol 2011;147:1157.

30. Jewell S. Elderly patients' participation in discharge decision-making 2. Br J Nurs 1996;5:1065

31. Hoffmann TC, Légaré F, Simmons MB, et al. Shared decision-making: what do clinicians need to know and why should they bother? Med J Aust 2014;201:35-9.

32. Anstey A, Edwards A. Shared decision-making in dermatology: asking patients, "What is important to you?" Br J Dermatol 2014:170:759-60.

33. Braddock CHIII, Edwards KA, Hasenberg NM, et al. Informed decision-making in outpatient practice: time to get back to basics. JAMA 1999;282:2313-20.

34. Donovan JL, Blake DR. Qualitative study of interpretation of reassurance among patients attending rheumatology clinics: "just a touch of arthritis, doctor?" BMJ 2000;320:541-4.

35. Harun NA, Finlay AY, Salek M, et al. The development and clinical evaluation of a "Traffic-light design" dermatology outpatient discharge information checklist. Br J Dermatol 2016;175:572-82. 